\title{
MATERIALS CALENDAR
}

\section{The Complete Guide To Technical Meetings \\ Of Interest To The Materials Science Community}

Exclusively in the MRS BULLETIN, notices of all major technical meetings of interest to the materials community have been brought together into a single, comprehensive calendar by the Materials Research Society. Prepared by Julia Phillips of AT \& T Bell Laboratories, the calendar is continuously updated and appears in every issue of the BULLETIN.

Meetings sponsored by or affiliated with the Materials Research Society appear in boldface type.

\section{AUGUST 1984}

1-3 The Physics of VLSI

Palo Alto, CA

K. Saraswat, McCullough 118, Stanford Univ., Stanford, CA 94305

(415) $497-2956$

1-3 3rd International Conference on MBE

San Francisco, CA

1.4 Topical Conference on Optical Effects in Amorphous

Semiconductors

Salt Lake City, UT

W. W. Havens, Jr., 335 E 45 St., New York, NY 10017

(212) 661.9404

Spectroscopy of Shallow Centers in Semiconductors

UC Berkeley, CA

4-14 27th International Geological Congress

Moscow, USSR

Sec., 27th Int. Geological Cong., Inst. of Lithosphere,

Academy of Sciences, 22 Staromonetry, Moscow 109180, USSR

6-10 International Conference on the Physics of Semiconductors San Francisco, CA

R. Z. Bachrach, Xerox Palo Alto Res. Ctr., 3333 Coyote Hill

Road,

Palo Alto, CA 94304

12-17 Meeting of the Electron Microscopy Society of America Detroit, MI

C. E. Lyman, Central Research \& Development Dept.

E. I. DuPont, Experimental Sta., Wlimington, DE 19898

(302) 772.4887

13-16 1st International Conference on the Structure of Surfaces Berkeley, CA

M. A. VanHove, Dept. of Chem., Univ. of CA, Berkeley, CA 94720

13-16 International Conference on Superlattices, Microstructures and Microdevices

Champaign-Urbana, IL

J. D. Dow, Dept. of Phys., Univ. of Notre Dame, Notre Dame, IN 46556

(219) $239-6407$
13-17 13th International Conference on Defects in Semiconductors Coronado, CA

13-17 6th International Conference on Thin Films Stockholm, Sweden

S. Berg, ICTF-6, Inst. of Tech., Uppsala Univ., Box 534, 75121 Uppsala, Sweden

13-17 International Conference on Luminescence

Madison, WI

W. H. Yen, Dept. of Physics, 1150 Univ. Av., Madison, WI 53706

13-18 8th European Conference on Electron Microscopy Budapest, Hungary

Congress Bureau, MOTESZ, Budapest, POB32, H-1361,

Budapest, Hungary

15-17 International Conference on Progress in Optical Physics ICO-Australian Acad. of Science

Melbourne, Australia

I. J. Wilson, CSIRO Div. of Chem. Phys., PO Box 160 ,

Clayton, Vic., Australia 3168

15-22 17th International Conference on Low Temperature Physics Karlsruhe, FRG

H. Hinsch, LT-17 Conf. Sec., Kernforschungszentrum, Postfach 3640, 7500 Karlsruhe, FRG

19-22 AIChE Summer National Meeting

Philadelphia, PA

AIChE, Meetings Dept., 345 E. 47 St., New York, NY 10017 (212) 705-7320

20-24 International Conference on Defects in Insulating Crystals Salt Lake City, UT

F. Luty, Dept. of Phys., Univ. of Utah, Salt Lake City, UT 84112

(801) $581-7446$

26-29 International Topical Meeting on Fuel Reprocessing and Waste Management

Jackson Hole, WY

W. McClure, PO Box 3807, Idaho Falls, ID 83401

26-31 188th National Meeting of the American Chemical Society Philadelphia, PA

American Chem. Soc., 1155 16th St., NW, Washington, DC 20036

27-31 3rd International Conference on Solid Films and Surfaces Sydney, Australia

D. J. Miller, Sch. of Phys., Univ. of New South Wales, POB 1, Kensington, NSW 2033 Australia

27-31 6th General Conference of the European Physical Society Prague, Czechoslovakia

Phys. Sec., Union of Czech. Mathematicians \& Physicists,

$\mathrm{Na}$ Slovance 2, 182 00, Prague 8, Czech.

29-31 3rd International Symposium on Physical Metallurgy

of Cast Iron

Stockholm, Sweden

Secretariat, Symposium on Cast Iron CI 3,

Materials Research Center,

Royal Institute of Technology

S-100 44 Stockholm, Sweden 
29-31 Conference on the Mechanical Characterization

of Load Bearing Fiber Composite Laminates

Brussels, Belgium

Prof. A. Cardon, Faculty of Applied Science

Telephone: $32-2 \cdot 641-2923$

\section{SEPTEMBER 1984}

3-7 5th International Conference on Rapidly Quenched Metals Wurzburg, FRG

RQ 5, Postfach 2253, D-6450 Hanau, FRG

4-7 International Conference on Fatigue

Birmingham, England

10-13 8th International Symposium on Chemical Reaction

Engineering

Edinburgh, Scotland

Dept. ISCRE, Conference Section, The Institution of Chemical

Engineers, 165-171 Railway Terrace, Rugby, Warwickshire

CV21 3HQ, England

10-14 5th International Titanium Conference

Munich, West Germany

12-13 Symposium on Solidification Fundamentals

Cleveland, $\mathrm{OH}$

J.F. Wallace, Dept. of Metallurgy \& Materials Science

Case Western Reserve University

Cleveland, $\mathrm{OH} 44106$

13-14 Kinetics and Mass Transport of Silicate \& Oxide Systems London, UK

R. Freer, Dept. Electrical \& Electronic Eng.,

North Staffordshire Polytech., Beaconside, Stafford ST18 OAD

17-20 TMS-AIME Conference

Detroit, MI

17.21 International Conference on Surface Modification

of Metals by Ion Beams

Heidelberg, West Germany

17.21 9th European Conference on Thermophysical Properties Manchester, UK

Mtg. Officer, IOP, 47 Belgrave Sq., London SW1X 8QX, UK

17-21 7th International Conference on Textures of Materials The Netherlands

Conf. Sec., PO Box 390, NL 3330 AJ Zwijndrecht,

The Netherlands

23-28 International Conference on the Science of Hard Materials Rhodes, Greece

25-28 Energy Pulse Modification of Semiconductors \& Related

Materials

Dresden, GDR

H. U. Jager, Centralinstitut fur Dernforschung, Rossendorf,

8051 Dresden, Postfach 19, GDR

\section{OCTOBER 1984}

7-12 Fall Meeting of the Electrochemical Society

New Orleans, LA

The Electrochemical Society

10 S. Main St, Pennington, NJ 08534-2896

9-11 Conference on Advances in Materials Technology for the Process Industries

Atlanta, GA

Dale Miller, Deputy Executive Dir. for Public Affairs,

Natl. Assoc. of Corrosion Engineers, PO Box 218340 ,

Houston, TX 77218
9-12 37th Gaseous Electronics Conference

Boulder, $\mathrm{CO}$

W. W. Havens, Jr., 335 E. 45 St., New York, NY 10017

(212) $661-9404$

21-26 5th International Meeting on Radiation Processing

San Diego, CA

J. Silverman, PO Box 3060, Woburn, MA 01888

29-2 Optical Society of America Annual Meeting

San Diego, Ca

Optical Society of America, 1816 Jefferson PI., NW,

Washington, DC 20036

29-2 Meeting of the Division of Plasma Physics of

the American Physical Society

Boston, MA

W.W. Havens, 335 E. 45th St., New York, NY 10017

31-2 4th International Conference on Ferrites

San Francisco, CA

$A$ dozen meetings added

Since the last BULLETIN issue

NOVEMBER 1984

12-14 8th Conference on the Application of Accelerators in Research and Industry

Denton, TX

J. L. Duggan

Physics Dept., North Texas State Univ., NT Box 5368,

Denton, TX 76203

(817) $565-3252$

13-15 International Conference on the Applications of Lasers

and Electro-Optics

Boston, MA

Laser Institute of America

5151 Monroe St., Ste. $118 \mathrm{~W}$, Toledo, OH 43623

25-30 AIChE Annual Meeting

San Francisco, CA

AIChE, Meetings, Dept., 345 E. 47 St., New York, NY 10017

(212) $705-7320$

26-30 MATERIALS RESEARCH SOCIETY ANNUAL MEETING

Boston Marriott Hotel/Copley Place

Boston, MA

J.B. Ballance, Executive Director

Materials Research Society

9800 McKnight Road, Suite 327

Pittsburgh, PA 15237 (412) 367-3003

27-30 30th Annual Conference on Magnetism

and Magnetic Materials

San Diego, CA

J.T. Scott, AIP, 335 E. 45th St., New York, NY 10017

\section{DECEMBER 1984}

4-7 31st National Vacuum Symposium

Reno, NV

N. Hammond, 335 E. 45 St., New York, NY 10017

\section{JANUARY 1985}

20-24 American Physical Society/AAPT General Meeting Toronto, ONT

[Continued on Page 18] 


\title{
DEFECTS IN INSULATORS
}

\author{
An MRS-Europe Symposium Report
}

The symposium on "Induced Defects in Insulators" covered many aspects of the interaction of radiation with insulating materials, with contributions from a broad scientific community. In all, 42 papers were presented, treating topics in an interdisciplinary manner.

A new field with an increasing interest is the study of the distribution of light ions and foil destruction after implantation of organic polymers. The research appears particularly important for lithography in the fabrication of semiconductor devices, where the lateral dimensions are pushed down to several Angstroms. The processes related to plasma erosion of non-metal first wall materials in fusion devices were reviewed and their relative importance was assessed, particularly for the problems connected with plasma contamination and mechanical or thermal stresses. It was also clear that radiation damage investigations in insulators assume a central role in nuclear waste management, because glass is a serious candidate material for waste disposal. A number of papers demonstrated the growing interest in optoelectronic materials for data processing, radiation effects in glass fiber cables, and electron-beam irradiation of electronic devices.

Several contributions were given on analysis techniques in insulators, such as nuclear techniques for hydrogen detection, ESR, AES, ESCA, and optical spectroscopy, emphasizing potential applications for defect characterization.
Ions or atoms with energies ranging from a few $\mathrm{eV}$ to $\mathrm{MeV}$ are formed in radiation belts, stellar winds, and cosmic rays, and as secondary particles from sputtering or knock-on processes. Their collisions may induce hot chemical reactions. Papers presented showed how laboratory simulations provide information on organic molecules in intersteller solids and on the potential abiotic formation of biomolecules in space.

It is worth remarking that many of the contributions on topics described above arose

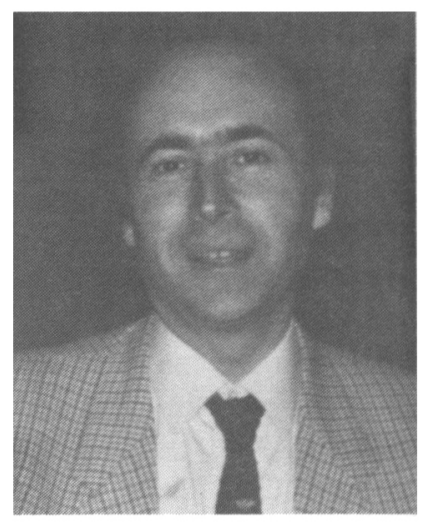

P. MAZZOLDI from the pursuit of the interdisciplinary approach required to connect technological applications to the basic interactions of energetic ions with insulators.

This meeting was an ideal bridge between the second (Albuquerque 1983) and the planned Third International Conference on Radiation Effects in Insulators (REI '85), which will be held in July 1985 at Guildford, Surrey.

\section{P. Mazzoldi \\ Padova, Italy}

\section{CALENDAR}

\section{[Continued from Page 9]}

\section{MARCH 1985}

24-28 AIChE Spring National Meeting

Houston, TX

AIChE, Meetings Dept., 345 E. 47th St., New York, NY 10017

(212) $705-7320$

25-29 American Physical Society General Meeting

Baltimore, MD

W. Havens, Jr., 335 E. 45 St., New York, NY 10017
25-27 American Physical Society Spring Meeting

Washington, DC

W. Havens, Jr., 335 E. 45th St., New York, NY 10017

MAY 1985

12-17 Electrochemical Society Spring Meeting

Toronto, Ontario, Canada

The Electrochemical Society

10 S. Main St., Pennington, NJ 08534-2896

13-17 International Conference on Nuclear Data

for Basic and Applied Science

Santa Fe, NM

Phillip G. Young, Conference Chairman,

Mail Stop B243, Los Alamos National Laboratory,

Los Alamos, NM 87545
APRIL 1985

15-18 MATERIALS RESEARCH SOCIETY SPRING CONFERENCE

San Francisco, CA

J.B. Ballance, Executive Director

Materials Research Society

9800 McKnight Road, Suite 327

Pittsburgh, PA 15237 (412) 367-3003
JULY 1985

23-25 Physical Interactions and Energy Exchange

at the Gas-Solid Interface

Hamilton, Ontario, Canada

Prof. J.A. Morrison

Institute for Materials Research

McMaster Univ, Hamilton, Ontario, Canada L85 4M1 